\title{
Improving Personal Happiness Through Couple Intervention: A Randomized Controlled Trial of a Self-directed Couple Enhancement Program
}

\author{
Peter Hilpert • Guy Bodenmann • Fridtjof W. Nussbeck • \\ Thomas N. Bradbury
}

\begin{abstract}
Although personal happiness is highly associated with social relationships, basic questions remain regarding the causal effect of improved social relationships on happiness. The main aim of this study was to test whether emotional and cognitive dimensions of personal happiness can be increased by means of a self-directed relationship enhancement program, which aims to increase relationship-relevant skills such as dyadic coping, communication, and conflict resolution. $N=220$ couples were randomly assigned either to an intervention or to a waiting list control group (survey: pre-, post-, 3- and 6-month follow-ups). Multi-group latent change score models reveal that (1) personal happiness can be increased through a couple intervention; (2) change in personal happiness was predicted by an increase in skills and relationship satisfaction through the intervention; (3) the least happy participants benefited most from the intervention. Improving spousal interactions may help people become and stay happier. Participants in this study did not relapse to their set point of personal happiness as could be expected by adaptation theory. Thus, not treating individuals directly, but rather the dynamic system of spousal interactions as a whole, offers a potentially very powerful area for happiness research.
\end{abstract}

\author{
P. Hilpert $(\bowtie)$ \\ Department of Psychiatry and Behavioral Sciences, University of Washington, 1100 NE 45th, Suite \\ 300, Office 346, Box 354944, Seattle, WA 98195-4944, USA \\ e-mail: hilpert@uw.edu \\ G. Bodenmann \\ Department of Psychology, University of Zurich, Zurich, Switzerland \\ F. W. Nussbeck \\ Department of Psychology, Bielefeld University, Bielefeld, Germany
}

T. N. Bradbury

Department of Psychology, University of California, Los Angeles, Los Angeles, CA, USA 
Keywords Happiness - Couples - Self-directed prevention - Relationship satisfaction · Multi-group latent change score model

\section{Introduction}

How to gain, how to keep, how to recover happiness is in fact for most men at all times the secret motive for all they do (James 1902, p. 76).

The pursuit of happiness has always been a fundamental goal for human beings (James 1902). Furthermore, it is well established that personal happiness is highly associated with social relationships, (see Diener and Seligman 2002; Fowler and Christakis 2008) and that the relationship with the intimate partner has, compared with other social relationships, the highest association with personal happiness (Headey et al. 1991). But although previous findings indicate that the causal association between personal happiness and relationship satisfaction (i.e., relationship happiness) is bi-directional (for example Lance et al. 1995), results from the last decade imply that the prior level of relationship satisfaction predicts later changes in personal happiness, but not vice versa (for example Dush and Amato 2005; Gustavson et al. 2012).

A possible causal association between relationship satisfaction and personal happiness is noteworthy because it opens a new perspective to improve personal happiness-namely by improving the relationship with the intimate partner. Thus far, there is already evidence that a lower level of well-being (i.e., symptoms of depression) can be improved by treating an individual's interpersonal system with couple interventions (i.e., couple therapy; Bodenmann et al. 2008; Leff et al. 2000) and a detailed case study show how pattern of change in dysthymia mutually influence the changes of each partner (Montesano et al. 2014). But one question remains: can personal happiness be improved by treating the dynamic system of couple interactions in a couple enhancement program? The present study aims to address this question.

\subsection{A Brief Overview of Theory and Empirical Findings of Personal Happiness}

Most often, personal happiness is used as a synonym for subjective well-being in the psychological literature (SWB; see for example Diener 1984). Happiness (or SWB) consists of two aspects: how people feel (i.e., the affective aspect) and how they think about their own lives (i.e., the cognitive aspect; Luhmann et al. 2012). The affective component of happiness (i.e., affective well-being, AWB) records either the intensity of one's emotions or the general hedonic level i.e., how happy/unhappy a person is with his/her life (Diener and Larsen 1993). Conversely, the cognitive aspect of happiness (cognitive wellbeing, CWB) is defined as a subjective evaluation of one's own mental state, which in itself is based on cognitive judgments about one's life (i.e., level of satisfaction with one's own life). But even though AWB and CWB are related constructs, they are distinct in respect to their variability over time (Eid and Diener 2004) and how they are associated with other constructs (Wiest et al. 2011). In a recent meta-analysis, Luhmann et al. (2012) could show that AWB and CWB differ in their associations across time with relationship related aspect such as marriage, divorce, and childbirth. For example, getting married had a stronger and more lasting effect on CWB than on AWB. Therefore, it is plausible to assume that couple interventions, intending to improve couple interactions, might have different effects on AWB and CWB. 
But how can personal happiness be achieved? The ancient Greek philosophers put forward various suggestions: Happiness can be achieved by maximizing pleasure and minimizing pain (hedonism, Aristippus), reducing desires (tranquility, Epicure), understanding what is good and bad (wisdom, Socrates), or by realizing one's own potential (eudaemonia, Aristotle). Based on these ancient suggestions, modern researchers have proposed that happiness can be achieved by "getting what you want" (desire theory; Conway and Ross 1984, p. 738), or by reaching worthwhile goals like friendship, freedom from disease and pain, love, and knowledge (objective list theory; Nussbaum 1992). These different goals can be achieved by a multitude of different behaviors. Recently, Seligman (2002) subsumed all of these paths (i.e., classes of behavior) into three main areas for the achievement of happiness: pleasure (and positive emotions), engagement, and meaning.

Although the pathways to happiness can principally be classified in terms of these three main areas, individuals are confronted with the problem of maintaining a long-lasting state of happiness. We will describe one mechanism shortly, which undermines approaches to increase lasting personal happiness: People quickly adapt to positive experiences and revert to hedonic neutrality (see adaptation theory or the hedonic treadmill model; Helson 1964) or to their genetic set point (i.e., happiness has a heritable set point; Diener et al. 2006). Thus, whatever people do or gain to improve their happiness, they become happier for some time but ultimately adapt to their new situation making them just as happy as before.

Despite this obstacle, there is growing recognition that lasting change of happiness is possible. Since the human potential movement in the 1960s, several interventions have successfully been developed to increase lasting happiness. Seligman and colleagues, for example, tested five different interventions in a randomized control trial (Seligman et al. 2005). Two of these enhanced happiness and decreased symptoms of depression for 6 months. Furthermore, a recent meta-analysis of 51 positive psychology interventions (Sin and Lyubomisky 2009) provides evidence that several interventions lead to lasting change in happiness. In addition, Diener et al. (2006) found that individuals are able to change their set point under certain conditions.

In addition, research over the last decades shows that good social relationships and thus positive social interactions are fundamental to personal happiness (Argyle 1987; Reis and Gable 2003). In other words, the quality of social interactions contributes to the level of happiness, which renders happiness to partly be a social phenomenon. Evidence shows for example that very happy people have "stronger romantic and other social relationships" (Diener and Seligman 2002, p. 81). Moreover, happiness seems to spread dynamically from person to person through social networks (Fowler and Christakis 2008), which indicates that being surrounded by happy people increases the likelihood of becoming happier in the future. Undoubtedly, social relationships are a key factor in personal happiness.

A closer analysis of the above-mentioned research that happiness is to a high degree the evaluation of social interaction reveals two striking facts about its general assumptions: (1) Although the pursuit of happiness has always been important for human beings as individuals and as members of social networks, it has always been considered as an individual quest; and (2), accordingly, the various interventions known to increase happiness have focused on training individuals and leave unaddressed potentially important social influences. To sum up, the strong focus on an individual's attempt to pursue personal happiness is surprising, based on the empirical evidence that has accumulated over the last decade. 
1.2 The Intimate Relationship as a Unique Social Relationship to Predict Personal Happiness

Among the various social relationships, for most people, the most important and most influential relationship in general is the one with their spouse (Berscheid and Reis 1998). Thus, it is plausible to presume that the quality of interactions with the intimate partner is among the most important factors for the development and maintenance of personal happiness. In order to understand intimate relationships, there are at least two distinct levels of how relationships can be assessed.

First, couple interactions depend on different domains such as conflict interactions, stress and coping interactions, and positive interactions (Hilpert et al. 2012). To examine these domains, participants report the frequency of specific behaviors (own and partner) and their satisfaction with these behaviors. But to our knowledge, there is no study examining the association between particular couple behaviors and personal happiness. Therefore, it is an open question whether specific behaviors exchanged in intimate relationship shape levels of personal happiness.

Second, level of satisfaction with the relationship is often measured by a subjective overall evaluation (i.e., indexed as marital satisfaction, relationship satisfaction, marital happiness, or relationship satisfaction). In the 1980s, Glenn and Weaver (1981) found that relationship satisfaction correlates with personal happiness $(r=0.41)$ and that relationship satisfaction is the best predictor for personal happiness in comparison with different domains: satisfaction with work $(r=0.14)$, friendships $(r=0.20)$, hobbies $(r=0.21)$, health $(r=0.25)$, or community $(r=0.19)$. More recently, Proulx et al. (2007) have shown a mean effect size of $r=0.37$ in a meta-analysis based on 93 studies between the association of relationship satisfaction and personal happiness.

But even though studies from the last three decades show that personal happiness and relationship satisfaction are strongly associated, the causal direction remains unclear: Do changes in relationship satisfaction cause changes in personal happiness, or vice versa; or is the causal association bi-directional (Proulx et al. 2007)? Few studies, based on survey data, examine the causal association between personal happiness and relationship satisfaction. Headey et al.'s (1991) and Lance et al.'s (1995) findings indicate a bi-directional causation. In contrast, studies from the last decade show a uni-directional path: the prior level of relationship satisfaction predicts later changes in personal happiness. For example, Hawkins and Booth (2005) and Dush and Amato (2005) show that prior problematic relationships (with lower level of relationship satisfaction) predict a later decrease in personal happiness, even after controlling for the initial level of relationship satisfaction. Dyrdal et al. (2011) report that relationship satisfaction is the better predictor for personal happiness than vice versa, based on a sample of women during the transition of pregnancy, infancy, and toddlerhood (3 years follow up). Finally, Gustavson et al. (2012) show that relationship problems (i.e., relationship un-satisfaction) predict lower levels of life satisfaction 15 years later. Studies from the last decade show that relationship satisfaction affects personal happiness, but there is less support of opposite causation. This is noteworthy because it opens a new perspective to improve personal happiness by improving the relationship with the intimate partner.

\subsection{Why Might Behavioral Changes Improve Intimate Relationships?}

Studies which examined the association between intimate relationships and personal happiness have focused mainly on relationship satisfaction to capture the impact of 
intimate relationships on personal happiness. But focusing on relationship satisfaction is not enough if one is interested to understand both how relationships cause personal happiness and how relationships can be altered to increase personal happiness. In other words, higher levels of relationship satisfaction cannot be the cause for a flourishing relationship, but is the result of positive, intimate, and caring behavior as well as handling problems and arguments in a functional way (e.g., Caughlin and Huston 2010; Rogge et al. 2006). Because it is reasonable to assume that positive behavior in the relationship not only increases relationship satisfaction but also personal happiness, it is crucial to examine how couples interact which each other (e.g., behavioral interactions in different situations). But taking couple behaviors into account leads to an additional question: Can personal happiness be caused by more positive and less negative behavior within the relationship or does behavior change first affect the level of satisfaction with the relationship, which in turn affects personal happiness?

\subsection{Couple Interventions Affect Personal (Un)happiness}

Although there are no studies examining the impact of relationship programs to improve couple interactions and personal happiness in the long run, there is already evidence that an individual's 'lower level of well-being' (i.e., depressive symptoms in particular) can be improved by couple interventions. For example, depressive symptoms, which might be considered as low level of well-being or unhappiness, can be reduced by marital therapy (Jacobson et al. 1991; Leff et al. 2000); and an increase in marital adjustment tends to reduce the incidence of depressive symptoms (Beach and O'Leary 1992). In addition, there is evidence that couple therapy is not only as effective in reducing depressive symptoms as cognitive-behavioral therapy (CBT; Beck et al. 1961) or interpersonal psychotherapy (IPT; Weissman et al. 2000), but also yields a better relapse rate after a 1.5-year period (Bodenmann et al. 2008). Thus, these results reveal that depressive symptoms can be reduced not only by treating the depression directly, but also by treating a person's interpersonal system.

Treating an individual's interpersonal system may reduce relationship unhappiness, but might it also improve personal happiness? Thus far, most studies inspecting the effects of relationship education programs investigate a reduction of distress or relationship satisfaction in the long term (see for example the following meta-analyses: Hawkins et al. 2008; Jakubowski et al. 2004). Using the same data set as the current study and testing the efficacy and effectiveness of a fully self-directed prevention program for dyads, Bodenmann et al. (2014) could show that women improved their behavior (dyadic coping behavior, positive communication, negative communication, conflict behavior) by means of the program and became more happy with their relationship, whereas men's change was less pronounced. ${ }^{1}$ But there are, as far as we know, no studies addressing the question of whether couple programs affect personal happiness. The goal of the present study is to examine whether individuals experience an increase in personal happiness when undergoing a distress prevention program for couples (in comparison with a control group). Because the experiment in the current study is based on a prevention program, the target audience is satisfied or relatively satisfied couples. This approach reflects the basic assumption of prevention. Couples should not be very distressed in order to prevent them

\footnotetext{
1 Though one articles has been published with this data set (Bodenmann et al. 2014), the current study is the only article to examine the effect of a self-directed couple intervention on individual happiness. Bodenmann et al. (2014) did examine the efficacy and effectiveness of the self-directed prevention program on dyadic outcomes.
} 
from becoming distressed. If couples are very distressed already, it is suggested that those couples should undergo couple therapy.

\subsection{The Current Study: The Self-directed Couple Coping Enhancement Program and Its Rationale}

Recently, self-directed relationship education programs have been developed. With the help of these programs, researchers and counselors hope to overcome one major limitation of face-to-face programs, namely their dissemination (Halford et al. 2008). In general, many couples might benefit from such programs, but are discouraged from participating by barriers such as cost, the amount of time required, the need to organize childcare, or the lack of anonymity (Halford et al. 2003).

The self-directed program used in this study is based on an evidence-based face-to-face couple distress prevention program called couples coping enhancement training (CCET; Bodenmann and Shantinath 2004). In contrast to the CCET program, the self-directed CCET-DVD program is supplied on an optical disc (DVD) and comprises five chapters including a total of $5 \mathrm{~h}$ video material (Bodenmann et al. 2014). The goal of the CCETDVD is to improve couple interaction by teaching skills. The first chapter focuses on providing theoretical inputs on stress and its impact on couples in general and that stress experience is based on subjective evaluation processes. The second chapter teaches individual coping skills. Individual coping skills are important because stress that has been dealt with can no longer spill over into the relationship or cross over to the partner. Thus, partners learn techniques such as using stress-balancing activities, avoiding unnecessary stress, calming strategies, and how to deal with stress that cannot be avoided. The third chapter teaches dyadic coping skills, because there is evidence that dyadic coping skills are associated with a reduction of stress and an increase of intimacy and relationship satisfaction (Bodenmann and Shantinath 2004). In this chapter, couples learn how to recognize stress, communicate appropriately, and provide effective support. The fourth chapter is about resolving conflicts. In general, distressed and non-distressed couples do not differ in the topics they disagree on (e.g., children, finance), but they differ in the way they handle disagreement (Karney and Bradbury 1995; further details about the program can be found in Bodenmann et al. 2014). For example, distressed couples show more negative interactions on verbal (i.e., content), nonverbal (e.g., gestures, mimic) and para-verbal levels (tone); their conflict episodes take longer; and the probability is higher to respond to a negative expression of the partner in a negative manner as well (Hahlweg 1991). Participants learn to recognize negative behavior, how negative coercion processes develop, and communication rules which help to avoid escalation (e.g., speaker/listener rule; Bodenmann 2012). Finally, in the fifth chapter, participants are taught about problem solving strategies, because dysfunctional problem solving interactions are associated with dissatisfying relationships (Schneewind and Gerhard 2002). They practice an adapted problem solving cycle including five steps (D'Zurilla and Goldfried 1971). Conflict resolution and problem solving are the classic skills for couple therapy and distress-prevention programs for couples.

\subsection{Hypotheses}

The present article aims to shed light on the effects of a self-directed couple intervention on personal happiness by addressing four core questions: Can personal happiness be increased by means of CCET-DVD couple intervention? If so, how do changes unfold 
over time? Do individuals with low or high initial levels of personal happiness benefit more from the intervention? And can changes in personal happiness be predicted by prior changes of the partner, an improvement in the skills taught by the intervention and/or an increase in relationship satisfaction?

Based on the recognition that depressive symptoms can be reduced by couple therapy, we hypothesize that participants will be able to increase their level of AWB and CWB (the affective and cognitive component of happiness) in comparison with a waiting list control group (H1). Second, if the adaptation theory is true, we expect that participants of the intervention group will reach their AWB and CWB peak shortly after the intervention, but will quickly adapt and thus revert to their initial level of AWB and CWB. On the contrary, based on the stable effects of couple therapy on reducing depressive symptoms, one could also assume stable effects on AWB and CWB of the program in the medium term $(\mathrm{H} 2)$. Third, we investigate who benefits most from the intervention: individuals who report higher or lower scores on AWB and CWB before the intervention (H3). Finally, we aim to explain changes in AWB and CWB: We assume effects of prior changes in AWB and CWB on later changes of AWB and CWB. We expect these effects to occur within partners (actor effects) but also to occur across partners (i.e., prior change in women's AWB affect later changes in men's AWB, so called partner effects; $\mathrm{H} 4 \mathrm{a}$ ); we also hypothesize that changes in AWB and CWB can be predicted by prior changes in skills (e.g., negative communication) through the intervention $(\mathrm{H} 4 \mathrm{~b})$; and, finally, we predict that prior changes in relationship satisfaction through the intervention predict a later increase in AWB and CWB ( $\mathrm{H} 4 \mathrm{c})$.

\section{Methods}

\subsection{Procedure}

For the present study, couples were recruited via articles in major newspapers in Switzerland. Each article described the new DVD-based couple distress prevention program and offered the DVD free of charge as an incentive to participants (market price $68 \mathrm{CHF}$, equivalent to $\$ 75$ in 2009). Couples could participate if they met the following criteria: they had to have been in a heterosexual relationship for at least 1 year, both partners had to give their written consent to participate, and they had to be free of any mental disorder. The Swiss National Science Foundation has approved this study with regard to ethical concerns.

In total, 330 couples initially participated in the research program. For the current study, only the experimental group and the control group will be used, hence, data from initially 220 couples, who were randomly assigned to either the experimental or control group, will be used (110 couples per group). ${ }^{2}$ Of these, 212 couples actually participated; the eight couples, who did not participate, declined the pre assessment and were immediately excluded from the study. For the analysis, we only included those couples, who completed at least pre and post assessments $(N=176$ couples; dropout rate $15.9 \%$, separated or

\footnotetext{
${ }^{2}$ This study is part of a larger study with a total of 330 couples (Bodenmann et al. 2014). In the larger study there were two experimental groups: (1) DVD group without any further support, and (2) a DVD group with technical telephone coaching. The experimental group with additional technical telephone coaching was excluded, because including an additional experimental group would increase the complexity of the study (e.g., differences in procedures, unwanted comparison of technical support versus self-directed, complexity of analyses). Because the main aim of the current study was to test a fully self-directed couple distress prevention program, which could potentially be disseminated online, we included the fully self-directed group with no further support.
} 
divorced during intervention $4.5 \%$ ). In the intervention group, $22.2 \%$ discontinued the study and $6.5 \%$ were removed from the study because of separation or divorce. In the control group, $3.8 \%$ discontinued the study and $1.0 \%$ were removed from the study because of separation or divorce. The rationale for excluding those couples who did not complete at least pre and post assessment was to rule out alternative explanations of the results (e.g., the intervention would appear to have an effect if unhappy couples drop out significantly more often from the intervention group than in the control group). Hence, data analyses were based on the sample of 176 couples who completed at least pre and post assessments and who, thus, showed a sufficient amount of compliance to the program.

At the beginning of the study, couples in the intervention group received the selfdirected program (DVD) directly after they filled in the first questionnaire and couples in the waiting list control group received the DVD at the end of the study after completion of the data collection. Participants were asked to fill in the questionnaires independently from their partners at home. They sent back the questionnaires in prepaid envelopes after each assessment. The four assessments took place at the beginning of the study (pre; 2 weeks before the experimental group started with the self-directed program), 9 weeks later (post; 2 weeks after completion of the program), 3 months after completion (follow-up 1) and 6 months after completion of the program (follow-up 2). Participants of the intervention group reported their processing time for each chapter on a protocol. Each of the five chapters takes about 60-90 min to complete (79 $\mathrm{min}$ on average), and partners can work either together or alone using the DVD; participants in the intervention group were advised to complete one chapter per week (Bodenmann et al. 2014).

\subsection{Participants}

Table 1 provides an overview about the demographics of the final sample $(N=176$ couples). Participants were between 20 and 67 years old (men: $M_{\text {age }}=41.3 ; S D_{\text {age }}=9.1$; range 20-65 years; women: $M_{\text {age }}=38.6$ years; $S D_{\text {age }}=8.6$; range $20-67$ years) and had been in their respective relationships for an average of 12.5 years $\left(S D_{\text {age }}=8.4\right.$; range 1-39 years). Most of the couples were married (71\%), and most couples had at least one child (73\%). There were no differences between the intervention and the control group in terms of marital status, number of children, or education. Overall, the sample was fairly typical of the Swiss population as a whole in terms of cohabitation, marital status, and number of children, but the level of education was slightly higher than the Swiss average.

\subsection{Measures}

\subsubsection{Demographics}

The demographic form was completed at the beginning of the study (pre), while all other self-reporting measures were completed at the pre-, post-, follow-up 1 and follow-up 2 assessment.

\subsubsection{Subjective Happiness Scale (SHS; Lyubomirsky and Lepper 1999; German Version by Proyer 2007)}

In order to assess the affective component of happiness (AWB), the subjective happiness scale was used. The subjective happiness scale asks respondents to rate three aspects of 


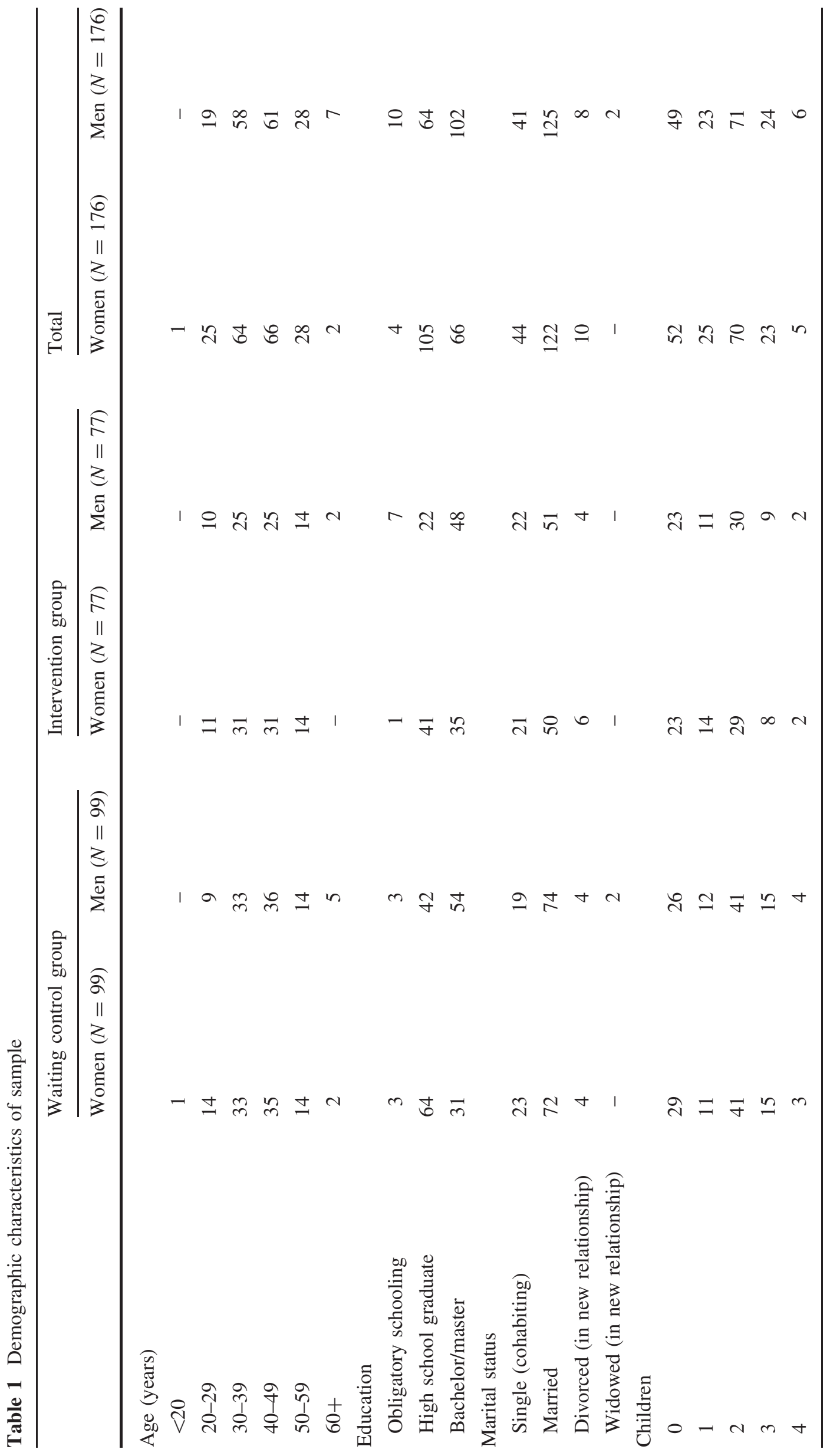


happiness: general happiness $(1=$ not a happy person, $7=a$ very happy person $)$, happiness relative to others $(1=$ less happy, $7=$ more happy $)$, and how happiness characterizes them as a person $(1=$ not at all, $7=$ a great deal $)$ with a total of four items. In this study, reliability (coefficient alpha) ranged from $\alpha=0.80$ to 0.88 across gender and all assessments. The subjective happiness scale has been widely used, comprises good validity (construct, convergent and discriminant validity), and has very good psychometric properties with reliability ranging from $\alpha=0.79$ to 0.94 through 14 samples (Lyubomirsky and Lepper 1999).

\subsubsection{Satisfaction with Life Scale (SWLS; Diener et al. 1985; German Version by Ruch et al. 2007)}

In order to assess the cognitive component of happiness (CWB), the satisfaction with life scale was used. The SWLS asked participants to rate their global satisfaction with life (e.g., I am satisfied with my life) with five items on a seven-point scale. The reliability of the SWLS is good (ranging from 0.82 to 0.89 ) across gender and all assessments in the current study. The SWLS has been widely used, comprises good validity, and has very good psychometric properties with reliability ranging from $\alpha=0.84$ to 0.87 in different samples (Diener 1994).

\subsubsection{Marital Communication Questionnaire (MCQ; Bodenmann 2000)}

The MCQ was used to measure both negative conflict communication (e.g., offending my partner and call him names) with 13 items and positive conflict resolution (e.g., searching for constructive solutions) with 6 items on a six-point scale $(1=$ never to $6=$ always $)$. For conflict communication, coefficient $\alpha$ ranged from $\alpha=0.78$ to 0.86 across gender and all assessments; for conflict resolution, coefficient $\alpha$ ranged from $\alpha=0.85$ to 0.90 across gender and all assessments. Difference scores were computed $\left(\mathrm{T}_{2}-\mathrm{T}_{1}\right)$ for men and women and added as so called covariates in the model. The MCQ has been widely used, comprises good convergent validity and has good psychometric properties with reliability of $\alpha=0.80$ for negative conflict communication and $\alpha=0.83$ for positive communication (Bodenmann 2000).

\subsubsection{Relationship Assessment Scale (RAS; Hendrick 1988; German Version by Sander and Böcker 1993)}

The RAS is used to assess relationship satisfaction, and measures both functional (e.g., In general, how satisfied are you with your relationship?) and dysfunctional aspects (e.g., How many problems are there in your relationship?) with seven items on a five-point scale. Coefficient $\alpha$ ranged from $\alpha=0.85$ to 0.92 across gender and all assessments. Difference scores were computed $\left(\mathrm{T}_{2}\right.$ minus $\left.\mathrm{T}_{1}\right)$ for men and women and added as covariates in the statistical model. The RAS has been widely used, comprises good construct-, convergent-, and discriminant validity and has good psychometric properties with reliability ranging from $\alpha=0.73$ to 0.88 through different samples (Hendrick et al. 1998).

\subsection{Statistical Analyses}

All four hypotheses can most appropriately be tested relying on a multi-group latent change score modeling (LCSM) approach for two change processes (one for men, one for 
women; McArdle 2009). That is, the change of personal happiness is modeled simultaneously for women and men reflecting the dependent data structure of couple data (see Kenny et al. 2006). Not only does the multi-group LCS model account for the dependent data structures by modeling two dependent change processes (see Fig. 1), but it additionally allows for potential group differences between the DVD and the WLC group. Since the multi-group LCS models are rather complex and demanding in terms of sample size requirements, we had to estimate two models: one for AWB and a second for CWB. We used common fit indices for structural equation modeling to evaluate the appropriateness of the models (see Schermelleh-Engel et al. 2003): $\chi^{2}$ value for absolute model fit, CFI and TLI for relative model fit, and RMSEA indicating closeness of fit.

Figure 1a presents the bivariate LCSM (baseline change model), where either AWB or CWB has been simultaneously modeled for female (upper chain) and male (lower chain) partners. The rectangles represent the observed scores at each assessment. The intercepts $\left(\mathrm{I}_{\mathrm{W}}\right.$ and $\left.\mathrm{I}_{\mathrm{M}}\right)$ represent the initial score on happiness for women and men, whereas the change scores $\left(\mathrm{C}_{\mathrm{W} 2}-\mathrm{C}_{\mathrm{W} 4}\right.$ and $\left.\mathrm{C}_{\mathrm{M} 2}-\mathrm{C}_{\mathrm{M} 4}\right)$ represent the changes in happiness at assessment 2-4 for women and men compared to their respective initial level. Although only one model is presented, the same model has been simultaneously estimated for the intervention group (DVD) and the waiting-list control group (WCG) in a multi-group approach. The mean change scores of the control group are expected to be non-significant, and can be used as a baseline for testing whether changes in the intervention group are significantly larger than changes in the control group. For the intervention group, significant mean change scores imply an increase or decrease in AWB or CWB in comparison to the changes in the control group.

If differences between the waiting list control group and the intervention group can be found ( $\mathrm{H} 1$; see Fig. 1a), further analyses with the intervention group are warranted: If there is an adaptation process during the course of the study, the mean change scores in the intervention group should be close to zero at later assessment; if the effects of the intervention are lasting, change scores should differ from zero even at later assessment (H2). In addition, inspecting associations between the intercept of AWB (CWB for the 2nd model) at Time 1 and change scores of the same construct allow for determining if individuals with lower or higher scores prior to the intervention tend to benefit most from the intervention (H3). In order to explain changes in AWB (CWB), the models were extended as shown in Fig. 1b, c (saturated models). In order to test, whether prior changes in AWB (CWB) after the intervention predict later changes of the same construct in the same or the other partner, paths (representing regressions) were inserted replacing the correlations of Fig. 1a. Actor effects can be found within the same (upper or lower) chain, partner-effects are depicted with "p" in Fig. 1b leading from one chain to the other (H4a). In order to test, whether prior changes in skills (i.e., changes in conflict resolution skills; H4b) or changes in relationship satisfaction $(\mathrm{H} 4 \mathrm{c})$ predict later changes in AWB $(\mathrm{CWB})$, the respective change scores (difference scores from T1 to T2 or T2 to T3 for conflict resolution or relationship satisfaction) were incorporated into the model (labeled as covariates) predicting AWB (CWB) change scores at assessments 3 and 4 (see Fig. 1c). Due to sample size restrictions we could only insert one change score of the predictors at a time, e.g., changes in conflict resolution for female and male partners.

SPSS 21 is used for descriptive statistics and MPlus 7.11 (Muthén and Muthén 19982013) for the structural equation models (LCSM). Because it is essential that couples completed the intervention in order to test its effect on personal happiness, we included only those couples in the analysis who at least submitted pre and post assessment. We implemented the full information robust maximum likelihood (FIML, MLR) estimator. 
(a)

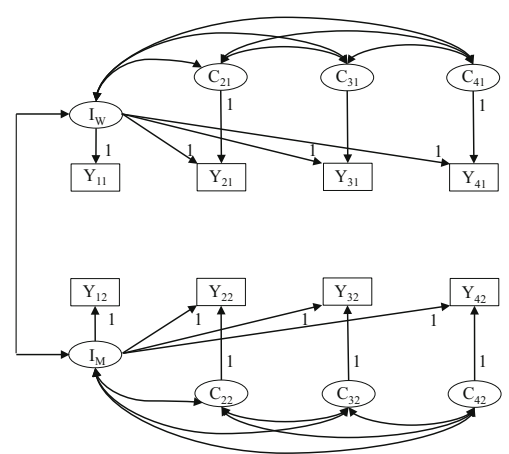

(b) $\mathrm{p}=$ Partner effects

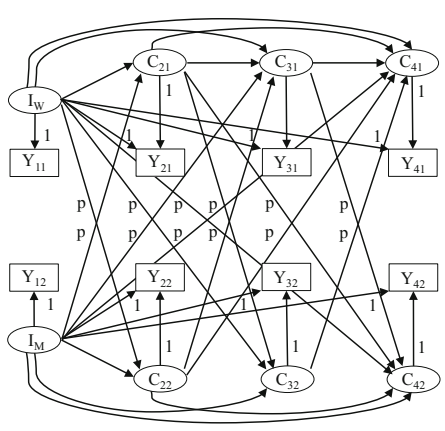

(c)

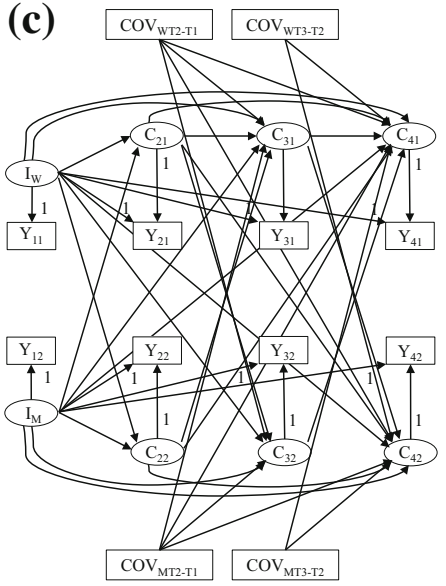

Fig. 1 The basic model (a) is built on a four-occasion structural equation model for two change processes (one for men, one for women). Simultaneously one latent change score model has been calculated for the intervention group and one for the control group (i.e., multi-group). For Time 1, latent intercepts were calculated $\left(\mathrm{I}_{\mathrm{W}}=\right.$ intercept for women; $\mathrm{I}_{\mathrm{M}}=$ Intercept for men) and latent change score for all other measures in time $\left(\mathrm{C}_{\mathrm{W} 2}-\mathrm{C}_{\mathrm{W} 4} ; \mathrm{C}_{\mathrm{M} 2}-\mathrm{C}_{\mathrm{M} 4}\right)$. In order to test hypothesis 4 , the model was extended. In order to test actor and partner effects (b), paths (representing regressions) were included in the model (partner-effects are depicted with "p"). In order to test, whether prior changes in skills or relationship satisfaction predict later changes in AWB (CWB), difference scores (i.e., covariates) from T1 to T2 or T2 to T3 for conflict resolution or relationship satisfaction were incorporated into the model (depicted with $\mathrm{COV}$ ) predicting later changes in AWB (CWB; see c)

\section{Results}

\subsection{Descriptive Statistics}

Table 2 presents means and standard deviations for both groups for all time points for AWB and CWB ( $N=176$ couples). Participants in the intervention and the control group did not differ significantly from each other at Time 1, indicating that the randomization was successful, at least with respect to the measured variables. Table 3 provides information for all predictor variables (positive and negative conflict communication, relationship satisfaction) of the intervention group (means, standard deviations, and difference scores). These results indicate that the sample was on average quite satisfied with the relationship $\left(\mathrm{M}_{\text {Women }}=3.92 ; \mathrm{M}_{\mathrm{Men}}=3.97\right.$; range 1-5); the level of positive conflict resolution was relatively high $\left(\mathrm{M}_{\mathrm{Women}}=4.35 ; \mathrm{M}_{\mathrm{Men}}=3.94\right.$; range 1-6) and the level of negative conflict communication was relatively low $\left(\mathrm{M}_{\mathrm{Women}}=2.23 ; \mathrm{M}_{\mathrm{Men}}=2.05\right.$; range 1-6).

Table 4 shows the correlations between AWB, CWB, negative conflict communication, positive conflict resolution, and relationship satisfaction. The correlation between AWB and relationship satisfaction $\left(r_{\text {Women }}=0.49, p<0.001 ; r_{M e n}=0.47, p<0.001\right)$ and CWB and relationship satisfaction $\left(r_{\text {Women }}=0.53, p<0.001 ; r_{\text {Men }}=0.59, p<0.001\right)$ are comparable to the findings of a recent meta-analysis (Proulx et al. 2007). The correlation of relationship satisfaction scores of both partners $(r=0.64, p<0.01)$ was significantly higher than that for AWB scores $\left(r=0.17, p=0.03\right.$; $\left.p_{\text {Fisher's z }}<0.001\right)$ or CWB scores $\left(r=0.21, p<0.01 ; p_{\text {Fisher's } \mathrm{z}}<0.001\right)$, indicating that relationship satisfaction scores are more closely associated between partners than are their AWB and CWB scores.

\subsection{Main Results for AWB}

The multi-group bivariate latent change score model for AWB fit well to the data $\left(\chi^{2}=31.5 ; d f=30 ; p=0.39 ; \mathrm{CFI}=0.998 ; \mathrm{TLI}=0.997 ; \mathrm{RMSEA}=0.037(90 \% \mathrm{CI}\right.$ 
Table 2 Means and SDs (in parentheses) of affective and cognitive well-being for both groups

\begin{tabular}{|c|c|c|c|c|}
\hline & \multicolumn{2}{|c|}{ Waiting control group ( $N=99$ couples $)$} & \multicolumn{2}{|c|}{ Intervention group ( $N=77$ couples $)$} \\
\hline & $\begin{array}{l}\text { Women } \\
M / S D\end{array}$ & $\begin{array}{l}\text { Men } \\
M / S D\end{array}$ & $\begin{array}{l}\text { Women } \\
M / S D\end{array}$ & $\begin{array}{l}\text { Men } \\
M / S D\end{array}$ \\
\hline \multicolumn{5}{|c|}{ AWB (range 1-7) } \\
\hline Time 1 & $5.02(1.14)$ & $5.25(0.94)$ & $5.18(1.05)$ & $4.99(1.02)$ \\
\hline Time 2 & $4.91(1.11)$ & $5.33(0.90)$ & $5.44(0.91)$ & $4.94(1.00)$ \\
\hline Time 3 & $4.97(1.04)$ & $5.21(0.87)$ & $5.41(0.86)$ & $5.13(0.91)$ \\
\hline Time 4 & 4.99 (1.09) & $5.24(0.98)$ & $5.37(0.99)$ & $5.21(0.89)$ \\
\hline \multicolumn{5}{|c|}{ CWB (range 1-7) } \\
\hline Time 1 & $5.18(1.15)$ & $5.19(0.88)$ & $5.29(1.09)$ & $5.13(0.88)$ \\
\hline Time 2 & $5.07(0.98)$ & $5.24(0.90)$ & $5.52(0.99)$ & $5.14(0.95)$ \\
\hline Time 3 & $5.08(0.93)$ & $5.12(0.94)$ & $5.71(0.80)$ & $5.35(0.84)$ \\
\hline Time 4 & $5.15(1.12)$ & $5.31(0.81)$ & $5.64(0.84)$ & $5.42(0.90)$ \\
\hline
\end{tabular}

$A W B$ affective well-being, $C W B$ cognitive well-being

0.00-0.09). The waiting-list control group and intervention group do not differ with respect to their initial level of AWB.

\subsubsection{AWB Women}

Women in the intervention group show significant changes in AWB in comparison with women of the control group, indicating that women can improve their level of the emotional aspect of happiness by undergoing couple interventions (H1). More specifically, women of the intervention group showed changes of AWB compared to their initial value at assessments 2, 3 and 4, indicating that change in AWB was resistant against adaptation, at least until the end of the study $\left(\mathrm{C}_{\mathrm{W} 2}=0.26, p=0.02\right.$, effect size Hedges's $g=0.25$; $\mathrm{C}_{\mathrm{W} 3}=0.23, p=0.02, g=0.22 ; \mathrm{C}_{\mathrm{W} 4}=0.17, p=0.05, g=0.16 ; \mathrm{H} 2$; see Fig. 2). Finally, we found that correlation coefficients between the initial level and change scores were negative, indicating that women with lower level in AWB prior to the intervention benefited most from the intervention $(-0.30 \leq r \geq-0.37$; H3).

\subsubsection{AWB Men}

Men in the intervention group show no significant changes of AWB in comparison with men in the control group at post assessment but a significant change at follow up 6 months after the intervention, indicating that men can in principal improve their level of the emotional aspect of happiness by undergoing couple interventions (H1). In particular, men in the intervention group showed a trend at assessment 3 and a significant change of AWB at assessment 4 (see Fig. 2). Finding a significant effect at the last measurement in time makes it difficult to determine whether this finding supports the adaptation theory or the assumption of stable change $\left(\mathrm{C}_{\mathrm{M} 4}=0.22, p=0.02, g=0.21\right.$; H2; Fig. 2). Finally, we found that correlation coefficients between the initial level and change scores were negative, indicating that men with lower level in AWB prior to the intervention benefited most from the intervention $(-0.13 \leq r \geq-0.33$; H3). 


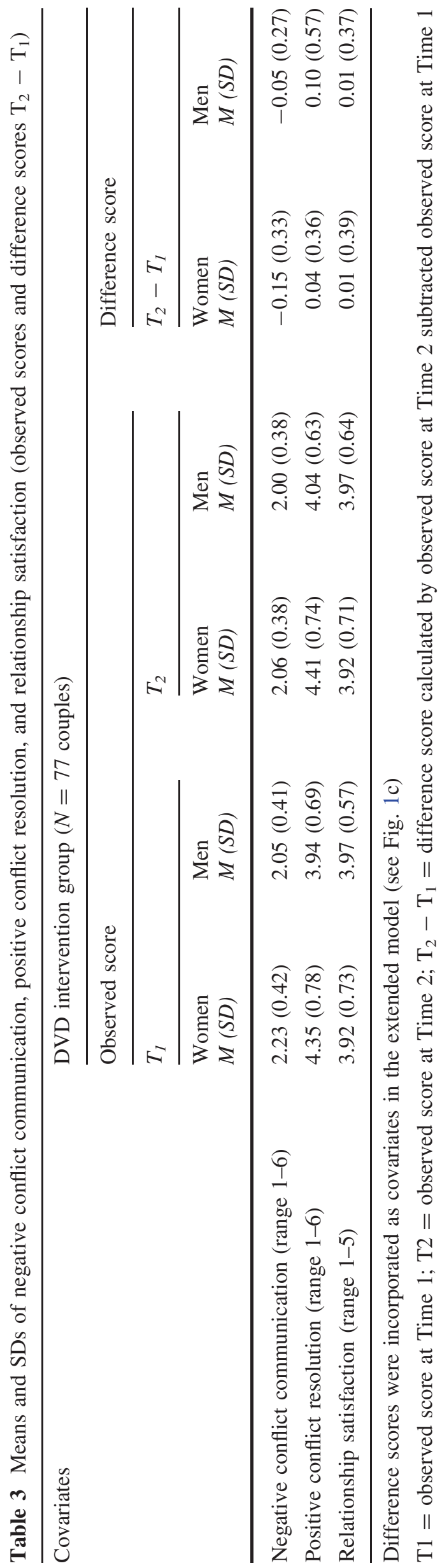


Table 4 Intercorrelations of all study variables for at Time 1

\begin{tabular}{|c|c|c|c|c|c|}
\hline & \multicolumn{5}{|c|}{ Intercorrelation } \\
\hline & 1 & 2 & 3 & 4 & 5 \\
\hline 1 Affective well-being (AWB) & $0.17 *$ & $0.69 * *$ & $-0.36 * *$ & $0.26 * *$ & $0.49 * *$ \\
\hline 2 Cognitive well-being (CWB) & $0.64 * *$ & $0.21 * *$ & $-0.27 * *$ & $0.22 * *$ & $0.53 * *$ \\
\hline 3 Negative conflict communication & $-0.19 *$ & $-0.23 * *$ & $0.33 * *$ & $-0.33 * *$ & $-0.39 * *$ \\
\hline 4 Positive conflict resolution & $0.35 * *$ & $0.38 * *$ & $-0.24 * *$ & 0.10 & $0.24 * *$ \\
\hline 5 Relationship satisfaction & $0.47 * *$ & $0.59 * *$ & $-0.42 * *$ & $0.43 * *$ & $0.64 * *$ \\
\hline
\end{tabular}

Intercorrelations for women are shown above the diagonal, and intercorrelations for men are shown below. Intercorrelations between spouses are shown in the diagonal (italic background)

$* p<0.05 ; * * p<0.001$

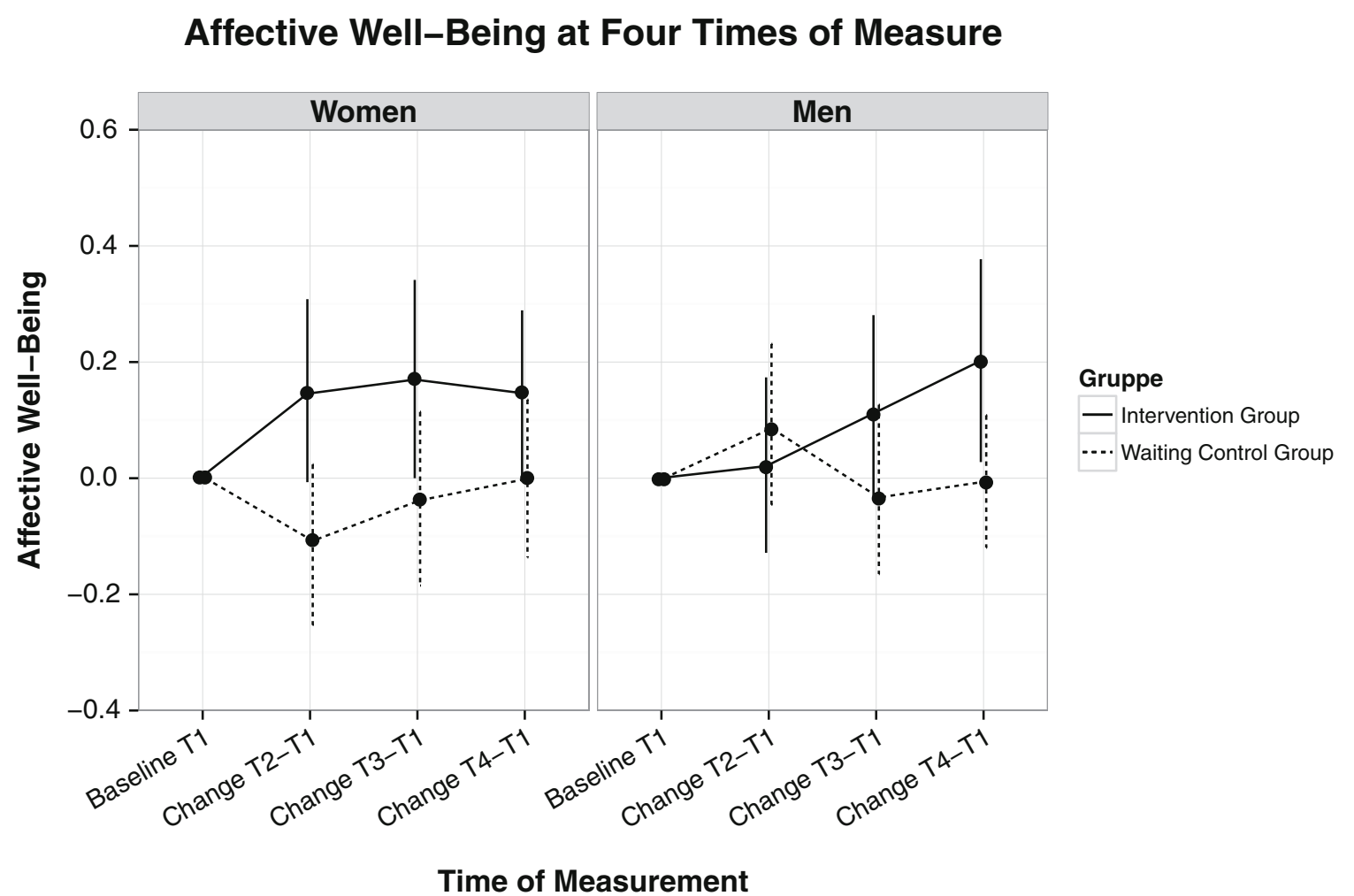

Fig. 2 The change scores of affective well-being between intervention and control group over the four times of measurements

\subsubsection{AWB Gender Effects}

Overall, the results reveal that women increased directly and stably in AWB through the intervention, whereas a delayed effect could be found for men. Men's AWB started to increase after 3 months and reached a significant increase 6 months after the interventions. But even though both men and women of the intervention group significantly improved the level of AWB in comparison to their baseline, their changes differ in comparison to the control group. Women of both groups start from the same level of AWB and women of the intervention group reach a higher level of AWB 6 month after the intervention. But men of 
the intervention group start from a (non-significant) lower level of AWB, reaching the same level of AWB as men of the control group 6 months after the intervention.

\subsubsection{Explanation of Change Processes for AWB}

For women, changes in AWB could not be explained by prior changes in AWB by the partner as predicted, but by actor effect, skills, and partner's increase in relationship satisfaction: Women's changes in AWB were predicted by a prior increase in AWB $\left(\beta_{T 3}=0.48, p<0.01 ; \beta_{T 4}=0.31, p<0.01\right)$, a decrease in negative conflict communication $\left(\beta_{T 4}=-0.55, p<0.01\right)$, and an increase in relationship satisfaction of the partner $\left(\beta_{T 3}=0.47, p<0.01\right)$. For men, changes in AWB could not only be explained by prior changes in AWB $\left(\beta_{T 3}=0.41, p<0.01 ; \beta_{T 4}=0.41, p<0.01\right)$, but also by changes of the partner: increase in women's AWB $\left(\beta_{T 4}=0.38, p<0.01\right)$ and by woman's increase in positive communication $\left(\beta_{T 4}=0.28, p<0.02 ; \mathrm{H} 4\right)$.

\subsection{Main Results for CWB}

The multi-group bivariate LCS models including CWB fit well to the data $\left(\chi^{2}=31.2\right.$; $d f=30 ; p=0.46 ;$ CFI $=1.000 ;$ TLI $=1.000 ;$ RMSEA $=0.008$ (90\% CI 0.00-0.08). The waiting-list control group and intervention group do not differ with respect to their initial level of CWB.

\subsubsection{CWB Women}

Women in the intervention group show significant changes of CWB in comparison with women of the control group, indicating that women can improve their level of the cognitive aspect of happiness by undergoing couple interventions (H1). Women in the intervention group showed significant changes of CWB at assessments 2, 3 and 4, indicating that the significant changes were resistant against adaptation, at least until the end of the study $\left(\mathrm{C}_{\mathrm{W} 2}=0.23, p=0.04, \quad g=0.28 ; \quad \mathrm{C}_{\mathrm{W} 3}=0.41, \quad p=0.00, \quad g=0.50 ; \quad \mathrm{C}_{\mathrm{W} 4}=0.30\right.$, $p=0.02, g=0.37$; H2; see Fig. 3) relationship satisfaction. Finally, correlation coefficients between the initial level and change scores were negative, indicating that women with lower levels in CWB prior to the intervention benefited most from the intervention $(-0.40 \leq r \geq-0.56$; H3).

\subsubsection{CWB Men}

Men in the intervention group show no significant changes of CWB in comparison with men of the control group at post assessment but a significant change at follow up 3 months after the intervention, indicating that men can improve in principal their level of the cognitive aspect of happiness by undergoing couple interventions (H1). Men in the intervention group showed a significant change of CWB at assessment 3 . Even though the change of the intervention group is significant at assessment 3 but not at assessment 4 in comparison with the control group, the comparison with the baseline (see Fig. 3) suggests the same trajectory as in AWB-a trend at assessment 3 and a significant change at time 4 $\left(\mathrm{C}_{\mathrm{M} 3}=0.22, p=0.04, g=0.24 ; \mathrm{H} 2\right)$. Finally, correlation coefficients between the initial level and change scores were negative, indicating that men with lower level in CWB prior to the intervention benefited most from the intervention $(-0.18 \leq r \geq-0.26$; H3). 


\section{Cognitive Well-Being at Four Times of Measure}

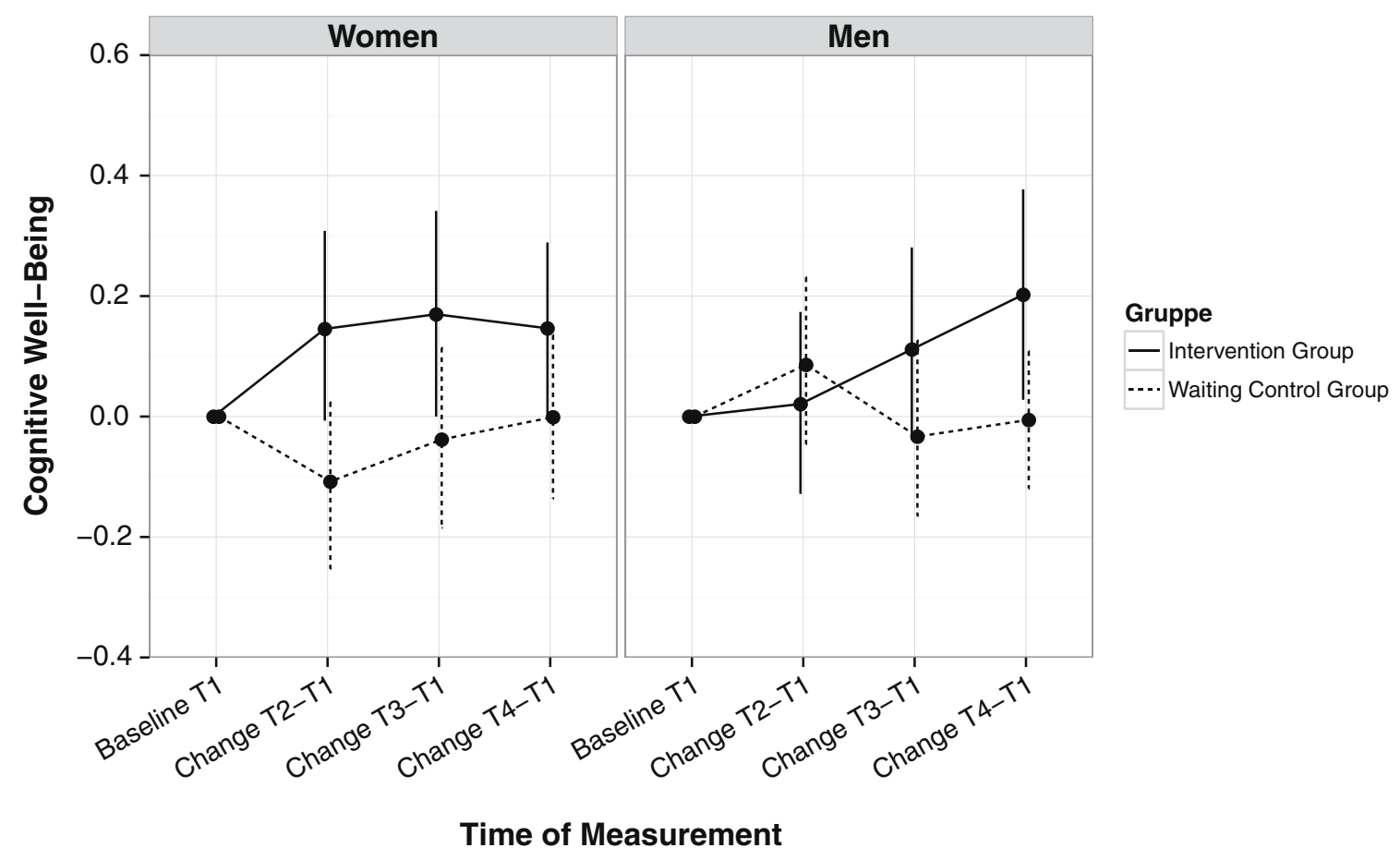

Fig. 3 The change scores of cognitive well-being between intervention and control group over the four times of measurements

\subsubsection{CWB Gender Effects}

Overall, women increased directly and stably in CWB through the intervention, whereas a delayed effect could be found for men. In comparison with the baseline, men's CWB started to increase after 3 months and reached a significant level 6 months after the interventions. But even though both men and women of the intervention group significantly improve the level of CWB in comparison with their baseline, their changes differ in comparison with the control group (Fig. 3). Women of both groups start from the same level of CWB and women of the intervention group reach a higher level of CWB 6 months after the intervention. But men of the intervention group start from a (non-significant) lower level of CWB, reaching a slightly higher level of CWB as men of the control group 6 months after the intervention.

\subsubsection{Explanation of Change Processes for CWB}

The significant changes in CWB could not be explained by prior changes in CWB by the partner, but by actor effects and by prior skill changes. It was found that women's changes in CWB at assessment 4 were predicted by prior changes in CWB $\left(\beta_{T 3}=0.54, p<0.01\right.$; $\left.\beta_{T 4}=0.44, p<0.01\right)$ and a decrease in negative conflict communication $\left(\beta_{T 4}=-0.41\right.$, $p=0.04)$. For men, the significant changes in CWB could be explained by prior changes in CWB $\left(\beta_{T 3}=0.53, p<0.01 ; \beta_{T 4}=0.59, p<0.01\right)$. Furthermore, we found a marginally association with relationship satisfaction $\left(\beta_{T 3}=0.58, p=0.06\right)$ but no effect of skills (H4). 


\subsection{Comparing AWB and CWB}

In contrast to the assumption that AWB and CWB are distinct concepts and, therefore, lead to different results through the intervention, the findings of AWB and CWB were surprisingly similar. AWB and CWB increased for women at assessment 2 and were relatively stable until the last measurement 6 months after the intervention, indicating that the changes due to the intervention were resistant against adaptation. For men, however, we found a delayed effect: no change at assessment 2, a trend 3 months later and a significant change 6 months after the intervention, at least in comparison with their baseline. Because the significant change occurred at the last assessment it cannot be determined whether the change is stable or not. Without exception, prior lower levels of AWB and CWB were associated with higher level of changes for both gender at all assessments for couples of the intervention group $(-0.13 \leq r \geq-0.56)$. This indicates that participants with initially lower levels of AWB and CWB benefited more through the intervention than the participants with higher levels of AWB or CWB.

Finally, we assumed that changes in AWB and CWB could be predicted by the partner's changes in AWB and CWB, changes in skills, and change in relationship satisfaction. Findings show that only men's changes in AWB could be predicted by prior changes in AWB of their partners. Furthermore, we might assume that changes within couples are more immediate. Results show that changes of CWB are significantly correlated between couples in the intervention group $(r=0.20, p=0.032)$ but not in the control group $(r=0.04, p=0.493)$, indicating that couples are changing at the same time. In addition, the results show that prior changes in skills and relationship satisfaction were good predictors to explain later changes in AWB and CWB.

\section{Discussion}

The pursuit of happiness has always been important for human beings, and many paths promise to increase personal happiness. There is evidence that good intimate relationships are fundamental to personal happiness (Diener and Seligman 2002) and that symptoms of depression can be reduced by treating an individual's interpersonal system with couple therapy (Bodenmann et al. 2008). Yet, it is an open question whether personal happiness can be improved by treating the system of couple interactions. Results obtained for the four specific hypotheses tested in this study are summarized below.

First, we sought to answer the question of whether personal happiness can be increased by teaching couples to improve relevant relationship skills in a self-directed couple program. The results revealed that the women and the men of the intervention group were significantly happier in comparison with the control group (between-group comparison). The results show some significant improvements for women at post-, follow-up 1, and follow-up 2 in both AWB and CWB in comparison with both their baseline and the control group; for men it was found that they increased in AWB at follow-up 2 and in CWB at follow-up 1 in comparison with the control group. In comparison with the baseline, however, men of the intervention group significantly increased just in AWB at follow-up 2 and CWB at follow-up 1. Thus, not only can depressive symptoms be reduced by couple therapy as shown before (Jacobson et al. 1991; Beach and O'Leary 1992), but the current findings support the assumption that personal happiness (AWB and CWB) can, in principle, be improved through a self-directed couple distress prevention program. Overall, the effects of the intervention on AWB and CWB were similar. Findings reveal that intimate 
relationships seem to affect individual emotional and cognitive perception similarly and the effects sizes are comparable with face-to-face relationship enrichment programs (see Shadish and Baldwin 2003; $0.32 \leq d \geq 0.48$ ).

The value of a couple-based approach also depends on how sustainable the intervention effects are. For the period of at least 6 months after the intervention, we found lasting changes in personal happiness for women, which is comparable to other interventions (e.g., Seligman et al. 2005). For men, we found a delayed effect, indicating that their AWB and CWB are significantly changing after 6 months in comparison with their baseline.

Second, we compared two different assumptions for the trajectory of happiness. Adaptation theory predicts that participants in the intervention group would reach their happiness peak shortly after the intervention, but would quickly adapt and rapidly revert to their initial level of happiness (at follow-up 1 or 2). Based on the findings of cognitivebehavioral couple therapy on depressive symptoms (Bodenmann et al. 2008), however, one could assume a change at post assessment and its maintenance at follow-up assessments. For women, the results are more in favor of the second assumption. In comparison to their initial level and in comparison with the changes of the control group, women were happier (AWB and CWB) at all assessments after the intervention and we did not find a significant decrease over time, indicating a stable change. Thus, we conclude that women's level of AWB and CWB can be improved in a medium term.

Men's changes, however, cannot be interpreted as clearly. We found significant changes in comparison with the control group for AWB at follow-up 2 and for CWB at follow-up 1. However, inspecting the plots about change related to baseline (within-group change, see Figs. 2, 3), we found a similar picture of change in men's AWB and CWB: no change at post assessment, but a trend at follow-up 1 and a change in happiness 6 months after the intervention, which is comparable to women's changes. These findings indicated a steady increase for men over time, even though statistically the unexpected change in CWB in the control group of the men at follow up 2 hinders that the change of the intervention group becomes significant. However, finding significant changes at only the last measurement in time does not allow for differentiating whether men's changes in AWB and CWB are stable. Overall, based on our data, it is difficult to answer why such gender effects occurred. Why did women react faster than men on the interventions? Why did men react to the intervention, but only after 6 months? It might be that relationships are more important for women. Talking with the partner about the relationship seems to have a direct effect on women, but not on men (Bernard 1982). Thus, we speculate that men react on actual and stable changes in the behavioral interactions through the interventions. However, these gender effects could also be explained by saying that the interventions somehow favor women's needs and interests. Maybe the focus of the intervention on communication or the way communication skills are trained (e.g., listen empathically and emotionally to the partner's problems) favors women's way of communication.

Third, we aimed to examine who benefits most from the intervention. The results (negative correlation of intercept and change variables) reveal that less happy participants benefited most from the intervention and that it is more difficult for happy participants to improve their level of happiness. This finding might be due to a ceiling effect that very happy people cannot report higher values than the maximum of the scale. However, averages of approximately 5 for CWB and AWB for both genders on a seven point scale indicate that nearly all participants could improve. Thus, this might be an interesting phenomenon that couple interventions/happiness interventions are more beneficial for less happy people. To our knowledge, there are no happiness interventions systematically testing who benefits within the intervention group. Thus, future research should examine in 
more detail who benefits from intervention and why. One option to test this has been used in the current study (correlation between intercepts and change scores). Another option could be to test whether the intercept at pre-assessment moderates the changes through the intervention (see author 1, author 2, in preparation). If we could know more about why an intervention works for some people and not for others, interventions could be (1) offered to people who would most likely benefit and not to others and (2) the interventions could be more tailor-made for specific groups. After examining who benefits most from the intervention, future research and theoretical models should also examine why less happy individuals increased more. It might turn out that less happy individuals are also less satisfied with their relationship and, therefore, a couple focused approach would seem to be the method of choice. However, it also might turn out that other variables moderate the effectiveness of the intervention. A better understanding of who benefits most and why would allow us to better understand the mechanism of happiness.

Fourth, we aimed to determine whether changes in happiness could be explained by the effects of the intervention, i.e., actor and partner effects, changes in skills, or changes in relationship satisfaction.

\subsection{Actor Effects}

Without exceptions, prior changes of AWB and CWB predicted later changes in the same factor, indicating that an initial increase is quite likely to continue.

\subsection{Partner Effects}

Results only revealed that prior changes of AWB in women predicted later changes in AWB in their partner. Thus, we assume that our prediction that changes in AWB and CWB in one person affect the partner 3 months later might be not that strong. Assuming that partner effects occur more instantly, we found that at least for CWB, changes within couples are correlated. Such correlations do not allow one to predict causal direction (men affect women or vice versa), but do allow one to conclude that changes of men and women are closely related.

\subsection{Skills}

The results of the study supported partially this hypothesis. Changes in skills (i.e., reduction of conflict communication; improvement of conflict resolution) also predicted later increase in AWB and CWB. This finding is noteworthy because it seems that skill improvement triggers different mechanisms for women and men. For women, a decrease in own conflict communication predicted a later increase in AWB and CWB; but for men, only an improvement of their wives' positive communication predicted later changes in AWB. Thus, improvement of skills had differential effects between men and women.

\subsection{Relationship Satisfaction}

Finally, we learned that changes in relationship satisfaction (pre- to post- assessment) were a good predictor for changes in AWB for women 6 months later. For example, women scoring one unit higher in relationship satisfaction throughout the intervention scored an average 0.47 (women) units higher in AWB and 0.58 (men) in CWB 6 months later. This 
finding supports the notion that an increase in relationship satisfaction might improve personal happiness, at least in a non-natural setting such as an intervention, and supports a dyadic approach to the pursuit of happiness.

In summary, it appears that improvements in personal happiness may be the result of partners learning, or being motivated to deploy, relationship relevant skills through the intervention (for main effects of the intervention see Bodenmann et al. 2014). Because these skills can be used in many different situations, it seems natural that they have a longer lasting effect on relationship satisfaction and personal happiness, explaining why no adaptation process could be found. Even though this is in line with findings that lasting change in happiness is best achieved by activity based activities and intentional activities and involve continual effort (Sheldon and Lyubomirsky 2006), it goes a step beyond and corresponds to the dynamic system of spousal interactions (Boker and Laurenceau 2006). Our finding that changes of CWB correlated among couples in the intervention group indicates that changes in one member of a couple affect changes in the other member. Such dynamic systems have already been described in terms of dysfunctional interactions (e.g., distance and isolation cascade, Gottman 1993). Based on the broaden and build theory of positive emotions (Fredrickson 2001), we might also expect such effects in dynamics systems for functional interactions. The broaden and build theory of positive emotions assumes that positive emotions broaden the thought-action repertoire and supports to the build-up of social resources. Thus, positive exchanges in one member of a couple as a result of the intervention might already force the other to change, leading to a positive shift. Therefore, we assume that lasting changes in happiness are caused by a positive shift in the dynamics of the couple's relationship as a result of the intervention.

Such shifts in a dynamic system might also constitute the major advantage in comparison with an intervention focusing just on individuals. In general, individuals need to invest much effort to maintain a change (e.g., see Sheldon and Lyubomirsky 2006), whereas we assume that systems can be changed by just initiating a change, and that the dynamics of (spousal) interaction will maintain that change (Boker and Laurenceau 2006), for some unknown period of time. Finally, focusing on dynamic systems like intimate relationships to pursue happiness might cancel out another problem, which was recently mentioned in the literature that "striving for [personal] happiness might damage people's connections with others and make them lonely" (Mauss et al. 2011). Focusing on intimate relationships might improve the relationship and, as a result of more closeness and intimacy, make individuals happier.

\subsection{Strengths and Limitations}

This study includes several strengths in terms of study design and statistical analyses, which reinforce our confidence in the results. First, the RCT approach is a clear strength of this study, which allows for disentangling intervention effect from unknown effects. Second, we used elaborated SEM approaches, simultaneously providing model estimates for different groups and controls for the interdependences of couple data. Third, the study not only conceptually takes into account whether happiness can be increased, but also examines in detail how changes unfold over time, who benefits from the intervention, and what might cause changes in happiness.

Despite these strengths, the study has several limitations. First, this study is based on self-reports. Second, the study design included a control group, but not a placebo control group. Therefore, it might be possible that the mere act of watching a DVD together, but not the actual content of that DVD, accounts for the effects observed. Indeed, recent studies indicate that changes in skills are not necessary for changes in relationship 
satisfaction (Rogge et al. 2013), suggesting that future studies will benefit from active control conditions. Finally, the relatively high dropout rate in the intervention group at post-assessment is a major concern. One explanation could be that couples of the control group received the incentive (i.e., the CCET-DVD) after finishing the last assessments, whereas couples of the intervention group got the DVD directly after finishing the first assessment, which may have led them to stop participating in the study. However, a closer examination of those dropouts revealed that they follow a missing at random mechanism and, therefore, we are confident that they do not bias the results.

\subsection{Implications}

This is the first study to our knowledge showing that couple intervention in general improves personal aspects of emotional and cognitive happiness. We believe that the findings of this study contribute to the body of knowledge by combining couple research and happiness research. Thus, not treating individuals directly, but rather engaging the dynamic system of intimate relationship as a whole, offers a new and potentially potent area for happiness intervention to add to the couple's approach to pursue happiness. These findings seem to be noteworthy and may provide a conceptual foundation for further interventions which seek to improve personal happiness by using the potential of treating the interpersonal system of intimate relationships.

Acknowledgments This research was supported by a research grant from the Swiss National Science Foundation (NCCR Sesam).

\section{References}

Argyle, M. (1987). The psychology of happiness. New York: Methuen.

Beach, S. R., \& O'Leary, K. D. (1992). Treating depression in the context of marital discord: Outcome and predictors of response for marital therapy versus cognitive therapy. Behavior Therapy, 23, 507-528.

Beck, A. T., Ward, C., \& Mendelson, M. (1961). Beck depression inventory (BDI). Archives of Genetic Psychiatry, 4, 561-571.

Bernard, J. (1982). The future of marriage. New York: World Publishing Company.

Berscheid, E., \& Reis, H. T. (1998). Interpersonal attraction and close relationships. In D. T. Gilbert, S. T. Fiske, \& G. Lindzey (Eds.), Handbook of social psychology (4th ed., pp. 193-281). New York: McGraw-Hill.

Bodenmann, G. (Ed.). (2000). Stress und Coping bei Paaren. [Stress and coping in couples]. Göttingen: Hogrefe.

Bodenmann, G. (2008). Dyadisches Coping Inventar (DCI). Testmanual. [Dyadic coping inventory; test manual]. Bern: Huber Testverlag.

Bodenmann, G. (2012). Verhaltenstherapie mit Paaren: Ein bewältigungsorientierter Ansatz [Behavioral therapy for couples: A skill based approach]. Bern: Huber.

Bodenmann, G., Hilpert, P., Nussbeck, F. W., \& Bradbury, T. N. (2014). Enhancement of couples' communication and dyadic coping by a self-directed approach: A randomized controlled trial. Journal of Consulting and Clinical Psychology, 82, 580-591. doi:10.1037/a0036356.

Bodenmann, G., Plancherel, B., Beach, S. R. H., Widmer, K., Gabriel, B., Meuwly, N., et al. (2008). Effects of coping-oriented couples therapy on depression: A randomized clinical trial. Journal of Consulting and Clinical Psychology, 76, 944-954. doi:10.1037/a0013467.

Bodenmann, G., \& Shantinath, S. D. (2004). The couples coping enhancement training (CCET): A new approach to prevention of marital distress based upon stress and coping. Family Relations, 53(5), 477-484. doi:10.1111/j.0197-6664.2004.00056.x.

Boker, S. M., \& Laurenceau, J. P. (2006). Dynamical systems modeling: An application to the regulation of the intimacy and disclosure in marriage. In T. A. Walls \& J. L. Schafer (Eds.), Models for intensive longitudinal data (pp. 195-218). New York: Oxford University Press. 
Caughlin, J. P., \& Huston, T. L. (2010). The flourishing literature on flourishing relationships. Journal of Family Theory \& Review, 2, 25-35. doi:10.1111/j.1756-2589.2010.00034.x.

Conway, M., \& Ross, M. (1984). Getting what you want by revising what you had. Journal of Personality and Social Psychology, 47, 738-748. [Reprinted in U. \& I. E. Hyman (Eds.) (2000), Memory observed (2nd Ed.). New York: Worth].

Diener, E. (1984). Subjective well-being. Psychological Bulletin, 95, 542-575. doi:10.1037//0033-2909.95. 3.542 .

Diener, E. (1994). Assessing subjective well-being: Progress and opportunities. Social Indicators Research, 31, 103-157. doi:10.1007/BF01207052.

Diener, E., Emmons, R. A., Larsen, R. J., \& Griffin, S. (1985). The satisfaction with life scale. Journal of Personality Assessment, 49, 71-75.

Diener, E., \& Larsen, J. R. (1993). The experience of emotional well-being. In M. Lewis \& J. M. Haviland (Eds.), Handbook of emotions (pp. 405-416). New York: Guilford.

Diener, E., Lucas, R. E., \& Scollon, C. N. (2006). Beyond the hedonic treadmill: Revising the adaptation theory of well-being. American Psychologist, 61, 305-314. doi:10.1037/0003-066X.61.4.305.

Diener, E., \& Seligman, M. E. P. (2002). Very happy people. Psychological Science, 13, 81-84. doi:10. $1111 / 1467-9280.00415$.

Dush, C. M. K., \& Amato, P. R. (2005). Consequences of relationship status and quality for subjective wellbeing. Journal of Social and Personal Relationships, 22, 607-627.

Dyrdal, G. M., Roysamb, E., Nes, R. B., \& Vitterso, J. (2011). Can a happy relationship predict a happy life? A population-based study of maternal well-being during the life transition of pregnancy, infancy, and toddlerhood. Journal of Happiness Studies, 12, 947-962. doi:10.1007/s10902-010-9238-2.

D'Zurilla, T. J., \& Goldfried, M. R. (1971). Problem soving and behavior modification. Journal of Abnormal Psychology, 78, 107-126.

Eid, M., \& Diener, E. (2004). Global judgments of subjective well-being: Situational variability and longterm stability. Social Indicators Research, 65, 245-277. doi:10.1023/B:SOCI.0000003801.89195.bc.

Fowler, J. H., \& Christakis, A. N. (2008). Dynamic spread of happiness in a large social network: Longitudinal analysis over 20 years in the Framingham heart study. British Medical Journal, 337, a2338. doi:10.1136/bmj.a2338.

Fredrickson, B. L. (2001). The role of positive emotions in positive psychology: The broaden-and-build theory of positive emotions. American Psychologist, 56, 218-226.

Glenn, N. D., \& Weaver, C. N. (1981). The contribution of marital happiness to global happiness. Journal of Marriage and the Family, 43, 161-168. doi:10.2307/351426.

Gottman, J. M. (1993). A theory of marital dissolution and stability. Journal of Family Psychology, 7, 57-75. doi:10.1080/01926189008250797.

Gustavson, K., Roysamb, E., von Soest, T., Helland, M. J., \& Mathiesen, K. S. (2012). Longitudinal associations between relationship problems, divorce, and life satisfaction: Findings from a 15-year population-based study. Journal of Positive Psychology, 7, 188-197. doi:10.1080/17439760.2012. 671346.

Hahlweg, K. (1991). Störung und Auflösung von Beziehungen: Determinaten der Ehequalität und -stabilität [Distress in relationships: Predicting marital quality and stability]. In M. Amelang, H. J. Ahrens, \& H. W. Bierhoff (Eds.), Partnerwahl und Partnerschaft. Göttingen: Hogrefe.

Halford, W. K., Markman, H. J., Kline, G. H., \& Stanley, S. M. (2003). Best practice in couple relationship education. Journal of Marital and Family Therapy, 29, 385-406. doi:10.1111/j.1752-0606.2003. tb01214.x.

Halford, W. K., Markman, H. J., \& Stanley, S. (2008). Strengthening couples' relationships with education: Social policy and public health perspectives. Journal of Family Psychology, 22, 497-505. doi:10.1037/ a0012789.

Hawkins, A. J., Blanchard, V. L., Baldwin, S. A., \& Fawcett, E. B. (2008). Does marriage and relationship education work? A meta-analytic study. Journal of Consulting and Clinical Psychology, 76, 723-734. doi:10.1037/a0012584.

Hawkins, D. N., \& Booth, A. (2005). Unhappily ever after: Effects of long-term, low-quality marriages on well-being. Social Forces, 84, 451-471. doi:10.1353/sof.2005.0103.

Headey, B., Veenhoven, R., \& Wearing, A. (1991). Top-down versus bottom-up theories of subjective wellbeing. Social Indicator Research, 24, 81-100. doi:10.1007/BF00292652.

Helson, H. (1964). Adaptation-level theory. New York: Harper \& Row.

Hendrick, S. S. (1988). A generic measure of relationship satisfaction. Journal of Marriage and the Family, 50, 93-98. doi:10.2307/352430.

Hendrick, S. S., Dicke, A., \& Hendrick, C. (1998). The relationship assessment scale. Journal of Social and Personal Relationships, 15, 137-142. doi:10.1177/0265407598151009. 
Hilpert, P., Bodenmann, G., Nussbeck, F., \& Bradbury, T. N. (2012). Predicting relationship satisfaction: A matter of conflict, positivity, or support? Family Science, 4, 110-120. doi:10.1080/19424620.2013. 830633.

Jacobson, N. S., Dobson, K., Fruzzetti, A. E., Schmaling, K. B., \& Salusky, S. (1991). Marital-therapy as a treatment for depression. Journal of Consulting and Clinical Psychology, 59, 547-557. doi:10.1037/ 0022-006X.59.4.547.

Jakubowski, S. F., Milne, E. P., Brunner, H., \& Miller, R. B. (2004). A review of empirically supported marital enrichment programs. Family Relations, 53, 528-536.

James, W. (1902). Varieties of religious experiences. New York: Mentor.

Karney, B., \& Bradbury, T. (1995). The longitudinal course of marital quality and stability: A review of theory, method, and research. Psychological Bulletin, 118, 3-34. doi:10.1037/0033-2909.118.1.3.

Kenny, D. A., Kashy, D. A., \& Cook, W. L. (2006). Dyadic data analysis. New York: The Guilford Press.

Lance, C. E., Mallard, A. G., \& Michalos, A. C. (1995). Tests of the causal directions of global-Life facet satisfaction relationships. Social Indicators Research, 34, 69-92. doi:10.1007/BF01078968.

Leff, J., Vearnals, S., Brewin, C., Wolff, G., Alexander, B., Asen, E., et al. (2000). The London depression intervention trial randomised controlled trial of antidepressants $\mathrm{v}$. couple therapy in the treatment and maintenance of people with depression living with a partner: Clinical outcome and costs. The British Journal of Psychiatry, 177, 95-100. doi:10.1192/bjp.177.2.95.

Luhmann, M., Hofmann, W., Eid, M., \& Lucas, R. E. (2012). Subjective well-being and adaptation to life events: A meta-analysis. Journal of Personality and Social Psychology, 102, 592-615. doi:10.1037/ a0025948.

Lyubomirsky, S., \& Lepper, H. S. (1999). A measure of subjective happiness: Preliminary reliability and construct validation. Social Indicators Research, 46, 137-155. doi:10.1023/A:1006824100041.

Mauss, I. B., Savino, N. S., Anderson, C. L., Weisbuch, M., Tamir, M., \& Laudenslager, M. L. (2011). The pursuit of happiness can be lonely. Emotion. doi:10.1037/a0025299.

McArdle, J. J. (2009). Latent variable modeling of differences and changes with longitudinal data. Annual Review of Psychology, 60, 577-605. doi:10.1146/annurev.psych.60.110707.163612.

Montesano, A., Feixas, G., Muñoz, D., \& Compañ, V. (2014). Systemic couple therapy for dysthymia. Psychotherapy, 51, 30-40. doi:10.1037/a0033814.

Muthén, L. K., \& Muthén, B. O. (1998-2013). Mplus user's guide (5th ed.). Los Angeles, CA: Author.

Nussbaum, M. (1992). Human functioning and social justice: In defense of Aristotelian essentialism. Political Theory, 20, 202-246. doi:10.1086/392123.

Proulx, C. M., Helms, H. M., \& Buehler, C. (2007). Marital quality and personal well-being: A metaanalysis. Journal of Marriage and Family, 69, 576-593. doi:10.1111/j.1741-3737.2007.00393.x.

Proyer, R. T. (2007). A recipe for a "positive psychology stew": German adaptations of nine questionnaires from positive psychology. In 10th Congress of the Swiss Society of Psychology (SSP), September 13th and 14th, 2007, Zurich, Switzerland.

Reis, H. T., \& Gable, S. L. (2003). Toward a positive psychology of relationships. In C. L. M. Keyes, \& J. Haidt (Eds.), Flourishing: Positive psychology and the life well-lived (pp. 129-159). Washington, DC: American Psychological Association. doi:10.1037/10594-006.

Rogge, R. D., Bradbury, T. N., Hahlweg, K., Engl, J., \& Thurmaier, F. (2006). Predicting marital distress and dissolution: Refining the two-factor hypothesis. Journal of Family Psychology, 20, 156-159. doi:10.1037/0893-3200.20.1.156.

Rogge, R. D., Cobb, R. J., Lawrence, E., Johnson, M. D., \& Bradbury, T. N. (2013). Is skills training necessary for the primary prevention of marital distress and dissolution? A 3-year experimental study of three interventions. Journal of Consulting and Clinical Psychology, 81, 949-961.

Ruch, W., Huber, A., Beermann, U., \& Proyer, R. T. (2007). Character strengths as predictors of the "good life" in Austria, Germany and Switzerland. In Romanian Academy, "George Barit" Institute of History, Department of Social Research (Ed.), Studies and researches in social sciences (Vol. 16, pp. 123-131). Cluj-Napoca: Argonaut Press.

Sander, J., \& Böcker, S. (1993). Die deutsche Form der Relationship Assessment Scale (RAS): Eine kurze Skala zur Messung der Zufriedenheit in einer Partnerschaft [The German version of the relationship assessment scale (RAS): A short scale for measuring satisfaction in a dyadic relationship]. Diagnostica, 39, 55-62.

Schermelleh-Engel, K., Moosbrugger, H., \& Mueller, H. (2003). Evaluating the fit of structural equation models: Test of significance and descriptive goodness-of-fit measures. Methods of Psychological Research Online, 8, 23-74.

Schneewind, K. A., \& Gerhard, A. K. (2002). Relationship personality, conflict resolution, and marital satisfaction in the first 5 years of marriage. Family Relations, 51(1), 63-71. doi:10.1111/j.1741-3729. 2002.00063.x. 
Seligman, M. E. P. (2002). Authentic happiness. New York: Free Press.

Seligman, M. E. P., Steen, T. A., Park, N., \& Peterson, C. (2005). Positive psychology progress: Empirical validation of intervention. American Psychologist, 60, 410-421. doi:10.1037/0003-066X.60.5.410.

Shadish, W. R., \& Baldwin, S. A. (2003). Meta-analysis of MFT interventions. Journal of Marital and Family therapy, 29, 547-570.

Sheldon, K. M., \& Lyubomirsky, S. (2006). Achieving sustainable gains in happiness: Change your actions, not your circumstances. Journal of Happiness Studies, 7, 55-86. doi:10.1007/s10902-005-0868-8.

Sin, N. L., \& Lyubomisky, S. (2009). Enhancing well-being and alleviating depressive symptoms with positive psychology interventions: A practice-friendly meta-analysis. Journal of Clinical Psychology, 65, 467-487. doi:10.1002/jclp.20593.

Weissman, M. M., Markowitz, J. C., \& Klerman, G. L. (2000). Comprehensive guide to interpersonal psychotherapy. New York: Basic Books.

Wiest, M., Schuez, B., Webster, N., \& Wurm, S. (2011). Subjective wellbeing and mortality revisited: Differential effects of cognitive and emotional facets of well-being on mortality. Health Psychology, 30, 728-735. 